Research Article

\title{
Effect of atenolol and enalapril treatment on oxidative stress parameters in patients with essential hypertension
}

\author{
Shashank Deoghare*, N. D. Kantharia
}

Department of Pharmacology, Government Medical College, Surat, Gujarat, India

*Presently at Cliantha Research Ltd, Ahmedabad, Gujarat, India

Received: 19 March 2013 Accepted: 13 April 2013

\section{*Correspondence to:}

Dr. Shashank Deoghare,

Email:

shashank.deo12@gmail.com

(C) 2013 Deoghare $\mathrm{S}$ et al. This is an open-access article distributed under the terms of the Creative Commons Attribution License, which permits unrestricted use, distribution, and reproduction in any medium, provided the original work is properly cited.

\begin{abstract}
Background: Oxidative stress has emerged as an important factor in the pathophysiology of hypertension. It also contributes to various complications associated with hypertension like vascular injury, atherosclerosis, renal dysfunction, and hypertensive end-organ damage. Present study was done to evaluate the effect of atenolol and enalapril, two commonly prescribed antihypertensive drugs, on oxidative stress in patients with hypertension.

Method: Sixty newly diagnosed hypertensive patients were randomly assigned to either atenolol $(n=30)$ or enalapril therapy $(n=30)$ and followed up for the period of three months. Twenty normotensive healthy volunteers served as control. Plasma malondialdehyde, superoxide dismutase and catalase levels were measured at the time of enrollment and at the end of three months of antihypertensive treatment.

Results: Plasma malondialdehyde was significantly increased whereas superoxide dismutase and catalase were significantly reduced in newly diagnosed hypertensive patients compared to controls. After three months of enalapril therapy, plasma malondialdehyde was significantly reduced and superoxide dismutase and catalase were significantly elevated. Atenolol therapy had no effect on these oxidative stress parameters.

Conclusions: Enalapril therapy significantly reduced oxidative stress in contrast to atenolol. Thus enalapril therapy may prove beneficial compared to atenolol by preventing oxidative stress and related complications in hypertension in view of life long therapy required for the treatment of hypertension.
\end{abstract}

Keywords: Oxidative stress, Reactive oxygen species, Atenolol, Enalapril, Essential hypertension

\section{INTRODUCTION}

Hypertension is the most common cardiovascular disease and a major cardiovascular risk factor that causes significant morbidity and mortality. Over the years it has emerged as an important public health problem in India because of the increasing longevity and prevalence of predisposing factors such as change in life style pattern, dietary habits, stress and obesity. The pathophysiology of hypertension involves a complex interaction of multiple factors. Compelling evidence indicates that reactive oxygen species (ROS) play an important role in the development of hypertension. Increased intracellular and extracellular production of ROS and activation of specific signaling pathways consequently lead to vascular injury, atherosclerosis, renal dysfunction, and hypertensive endorgan damage. ${ }^{1,2}$

These findings have evoked considerable interest because developing strategies that target ROS in treatment of hypertension may be useful in minimizing vascular injury and renal dysfunction and thereby prevent or regress hypertensive end-organ damage. Some of the beneficial effects of classic antihypertensive agents such as $\beta$ adrenergic blockers, ACE inhibitors, $\mathrm{AT}_{1}$ receptor antagonists, and $\mathrm{Ca}^{2+}$-channel blockers may be mediated in part by decreasing vascular oxidative stress. ${ }^{3}$

Atenolol and Enalapril are among the most commonly prescribed antihypertensive agents. These drugs have a well proven role in the treatment of hypertension. However these drugs do not seem to confer equivalent cardiovascular protection. Many studies have shown superiority of enalapril over atenolol in overall cardiovascular outcomes in hypertensive patients despite comparable control of blood pressure. Some of these effects may be attributed to differences in these drugs in reducing oxidative stress. Some studies have shown that atenolol can significantly decrease oxidative stress $^{4,5}$ while others have reported ineffectiveness of atenolol in 
reduction of oxidative stress. ${ }^{6,7}$ Similarly some studies with enalapril have shown that it can reduce the oxidative stress ${ }^{8,9}$ while others contradict the statement. ${ }^{10}$ So this study was done to evaluate the association between oxidative stress and hypertension and to study the effect of atenolol and enalapril therapy on various oxidative stress parameters.

\section{METHODS}

The study was conducted at the New Civil Hospital, Surat during September 2010 to March 2011. The study was approved by the Institutional Ethics Committee.

Subjects: Sixty newly diagnosed patients with essential hypertension according to Joint National Committee VII classification were included in the study. A group of 20 healthy normotensive subjects matched for age and sex was selected as control. Patients with congestive heart failure, cerebrovascular or coronary artery disease, diabetes, renal or liver disease were excluded from the study. Excluded also were smokers, alcoholics and subjects taking any medication known to affect oxidative stress. Informed consent was obtained from all participants after explaining study details.

After enrollment, hypertensive patients were divided into two groups randomly. The first group $(n=30)$ was treated with atenolol and the second group $(n=30)$ was treated with enalapril for the period of three months. Blood pressure measurement and estimation of plasma malondialdehyde, blood superoxide dismutase and catalase activity was done at the time of enrollment and at the end of three months treatment period. Some characteristics of control and patient groups are given in Table 1.

Blood sample collection: In all subjects, $5 \mathrm{ml}$ venous blood sample was collected in Na-EDTA $(1 \mathrm{mg} / \mathrm{ml})$ tubes and immediately centrifuged at $3000 \mathrm{rpm}$ for $15 \mathrm{~min}$. The plasma separated was used for malondialdehyde estimation. The cells were washed with normal saline three times and $0.5 \mathrm{ml} \mathrm{RBCs}$ was subjected to lysis by adding $3 \mathrm{ml}$ ice cold distilled water. Haemoglobin in the hemolysate was precipitated by adding $1 \mathrm{ml}$ ethanol and $0.6 \mathrm{ml}$ chloroform. The mixture was mixed thoroughly on the vortex and centrifuged at $3000 \mathrm{rpm}$ for 15 minutes. Supernatant was used for estimation of SOD and catalase activity.

Estimation of plasma malondialdehyde: Plasma malondialdehyde levels were estimated as per the method described by Ohkawa et al. ${ }^{11}$ Briefly, $0.5 \mathrm{ml}$ of plasma, 0.5 $\mathrm{ml}$ of normal saline, $1 \mathrm{ml}$ of $20 \%$ trichloroacetic acid (TCA) and $0.25 \mathrm{ml}$ of TBA reagent $(200 \mathrm{mg}$ of thiobacbituric acid in $30 \mathrm{ml}$ distilled water and $30 \mathrm{ml}$ of acetic acid) were added to a test tube and kept in a boiling water bath at $95^{\circ} \mathrm{C}$ for one hour. The tube was then centrifuged at $3000 \mathrm{rpm}$ for 10 minutes at room temperature. The absorbance of clear supernatant was measured at $535 \mathrm{~nm}$. Values were expressed in terms of nmol of malondialdehyde per millilitre $(\mathrm{nmol} / \mathrm{ml})$ of plasma.
Estimation of superoxide dismutase: The activity of SOD in erythrocytes was determined by the method described by Marklund and Marklund ${ }^{12}$ with some modifications as described by Nandi and Chatterjee. ${ }^{13}$ In brief, $50 \mu \mathrm{l}$ hemolysate was added to $1 \mathrm{ml}$ of air equilibrated Tris- $\mathrm{HCl}$ buffer $(\mathrm{pH}$ 8.2) and allowed to incubate at room temperature. The reaction was started by addition of $10 \mu \mathrm{L}$ of freshly prepared pyrogallol solution $(2.6 \mathrm{mM}$ pyrogallol in $10 \mathrm{mM} \mathrm{HCl})$. The rate of increase in the absorbance at $420 \mathrm{~nm}$ was recorded for 2 minutes, from 1 minute $30 \mathrm{sec}$ to 3 minute $30 \mathrm{sec}$ in a spectrophotometer. The activity of SOD was measured as $50 \%$ inhibition of auto-oxidation of pyrogallol and expressed as $\mathrm{U} / \mathrm{gHb}$.

Estimation of catalase: Measurement of catalase was done by the method described by Sinha. ${ }^{14} 0.1 \mathrm{ml}$ of hemolysate was added to $1 \mathrm{ml}$ of air equilibrated phosphate buffer and $0.4 \mathrm{ml}$ (800 micromoles) of $6 \%$ $\mathrm{H}_{2} \mathrm{O}_{2}$ solution was added to it. The reaction was stopped exactly after one minute by adding $2 \mathrm{ml}$ of potassium dichromate solution (5\% potassium dichromate and glacial acetic acid in 1:3 proportion). The test tube was then heated for 10 minutes in water bath. The optical density was then measured at $570 \mathrm{~nm}$. Total number of moles of $\mathrm{H}_{2} \mathrm{O}_{2}$ consumed in the reaction was determined. Catalase activity was expressed as $\mu \mathrm{mol}$ of $\mathrm{H}_{2} \mathrm{O}_{2}$ consumed/min/mg Hb.

Statistical analysis: All results are expressed as mean \pm SD. One way ANOVA with Bonferroni correction was used to determine significance between different groups. Paired t test was used to compare pre-treatment and post treatment values within the atenolol and enalapril group. Values of $\mathrm{p}<0.05$ were taken to show a significant difference.

\section{RESULTS}

Baseline mean systolic and diastolic blood pressures were $158.6 \pm 10.6$ and $101.1 \pm 7.3 \mathrm{~mm} \mathrm{Hg}$ in the atenolol group, $161.3 \pm 11.6$ and $103.4 \pm 8.4 \mathrm{~mm} \mathrm{Hg}$ in the enalapril group and $118.4 \pm 7.8$ and $78.2 \pm 4.6 \mathrm{~mm} \mathrm{Hg}$ in the control group (Table 1). After three months of antihypertensive therapy, SBP and DBP were $124.2 \pm 6.5$ and $77.8 \pm 5.4 \mathrm{~mm} \mathrm{Hg}$ in the atenolol group and $126.1 \pm$ 7.4 and $79.7 \pm 4.9 \mathrm{~mm} \mathrm{Hg}$ in the enalapril group. DBP levels in both the treatment groups were similar to those of the control group. SBP levels in both the groups were higher than the control group, but remained within normal limits (Figure 1).

Before antihypertensive therapy, plasma malondialdehyde level was significantly raised in hypertensive patients of both groups in comparison to control group ( $p<0.001$ ). After three months of therapy, mean plasma MDA level decreased significantly in enalapril group ( $\mathrm{p}<0.01$ ). However, the decrease in MDA level in atenolol group was not statistically significant $(\mathrm{p}>0.05)$ (Table 2). 
Table 1: General characteristics of the study population.

\begin{tabular}{|lllll|}
\hline Variable & & Control $(\mathrm{n}=20)$ & Atenolol $(\mathrm{n}=\mathbf{3 0})$ & Enalapril $(\mathrm{n}=\mathbf{3 0})$ \\
\hline Age & $55 \pm 6$ & $54 \pm 6$ & $56 \pm 7$ \\
\hline \multirow{2}{*}{ Gender } & Male & 14 & 22 & 24 \\
\cline { 2 - 5 } & Female & 6 & 8 & 6 \\
\hline Systolic BP & & $118.4 \pm 7.8$ & $158.6 \pm 10.6^{*}$ & $161.3 \pm 11.6^{*}$ \\
\hline Diastolic BP & $78.2 \pm 4.6$ & $101.1 \pm 7.3^{*}$ & $103.4 \pm 8.4^{*}$ \\
\hline
\end{tabular}

Data shown are mean $\pm \mathrm{SD}, * \mathrm{p}<0.001$ vs. control

Table 2: Effect of atenolol and enalapril treatment on oxidative stress parameters.

\begin{tabular}{|c|c|c|c|c|c|}
\hline & \multirow{2}{*}{ Control } & \multicolumn{2}{|l|}{ Atenolol } & \multicolumn{2}{|l|}{ Enalapril } \\
\hline & & $\begin{array}{l}\text { Before } \\
\text { treatment }\end{array}$ & $\begin{array}{l}\text { After } \\
\text { treatment }\end{array}$ & $\begin{array}{l}\text { Before } \\
\text { treatment }\end{array}$ & $\begin{array}{l}\text { After } \\
\text { treatment }\end{array}$ \\
\hline $\operatorname{MDA}(\mathrm{nmol} / \mathrm{ml})$ & $4.12 \pm 0.79$ & $5.31 \pm 1.35^{*}$ & $5.01 \pm 1.2^{\alpha}$ & $5.23 \pm 1.24^{*}$ & $4.54 \pm 1.14^{\#}$ \\
\hline $\mathrm{SOD}(\mathrm{U} / \mathrm{gHb})$ & $1076 \pm 142$ & $885 \pm 173^{*}$ & $917 \pm 165^{*}$ & $898 \pm 161^{*}$ & $1024 \pm 184^{\#}$ \\
\hline Catalase (U/gHb) & $5146 \pm 412$ & $4566 \pm 627^{*}$ & $4675 \pm 585^{\alpha}$ & $4602 \pm 660^{*}$ & $4845 \pm 573^{\infty}$ \\
\hline
\end{tabular}

Data shown are mean $\pm \mathrm{SD}, * \mathrm{p}<0.001$ vs. control, $\alpha \mathrm{p}<0.01$ vs. control, $\# \mathrm{p}<0.01$ vs. before treatment, $\infty \mathrm{p}<0.05$ vs. before treatment

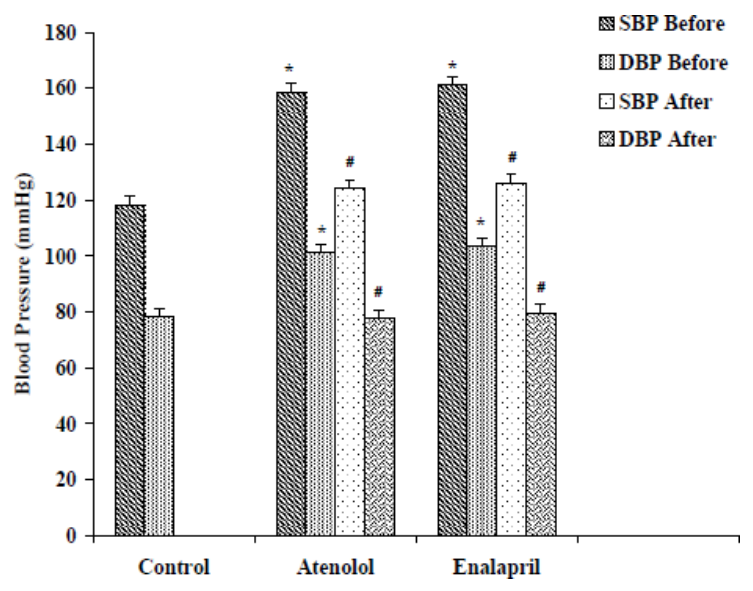

Figure 1: Systolic and diastolic blood pressure in patient and control groups.

(* $\mathrm{p}<0.01$ vs. control, \# $\mathrm{p}<0.01$ vs. before treatment)

Erythrocyte superoxide dismutase, a component of antioxidant enzyme system, was also measured before and after treatment. In hypertensive patients, before treatment, mean SOD activity was significantly decreased in both groups compared to control group ( $p<0.001)$. After three months of therapy with enalapril, SOD activity was significantly increased $(p<0.01)$, whereas at the end of three months therapy with atenolol, SOD activity increased but this change was not statistically significant $(\mathrm{p}>0.05)$ (Table 2$)$.

Erythrocyte catalase level was significantly decreased in the hypertensive patients compared to controls ( $p<$ $0.001)$. In the enalapril group, at the end of three months treatment, catalase level was significantly increased ( $\mathrm{p}<$ $0.05)$. However, in atenolol group, the increase in catalase level was not statistically significant $(\mathrm{p}>0.05)$ (Table 2).

\section{DISCUSSION}

In this study, we examined plasma malondialdehyde level, which is an index of lipid peroxidation, and erythrocyte SOD and catalase that are the components of antioxidant system, in patients of essential hypertension, and the effects of atenolol and enalapril on these parameters after three months therapy.

Increased oxidative stress has been demonstrated in various animal models of hypertension as well as in human hypertension. ${ }^{15}$ In human and animal models, it is believed that an imbalance between generation of ROS and antioxidant defense mechanisms may contribute to the pathogenesis of hypertension and its complications. ${ }^{16,17}$ Hypertension leads to increased expression and activity of ROS generating enzymes such as NADPH oxidase, 
xanthine oxidase and uncoupled NOS which act as a primary sources of the $\mathrm{O}_{2} \cdot{ }^{-}, \mathrm{H}_{2} \mathrm{O}_{2}$ and. $\mathrm{OH}$ radicals as the end product. Due to the high susceptibility of lipid membranes to peroxidation, the free radicals easily peroxidate the lipid membranes, and MDA is generated as a final product of peroxidation. MDA itself causes peroxidation, and accelerates peroxidation process by synergizing with free radicals. ${ }^{18}$

Consistent with these findings we found an increase in mean plasma MDA level, and a significant decrease erythrocyte SOD and catalase activity in essential hypertensive patients. Increased MDA levels are due to increased lipid peroxidation by ROS and decreased level of antioxidant enzymes may be due to decreased expression of the genes for these enzymes or inactivation of these enzymes by ROS. However it is unclear whether or not oxidative stress is the cause or the consequence of hypertension and it needs further evaluation.

In this study, we found that following therapy with enalapril, the mean plasma MDA level decreased significantly and SOD and catalase levels showed significant increase whereas therapy with atenolol did not produce any beneficial effect on these oxidative stress parameters even though both of these agents normalized SBP and DBP in these patients. This suggests that enalapril but not atenolol may prevent oxidative stress in hypertensive patients independent of its blood pressure lowering effect.

It is reported that angiotensin II (Ang II) increases superoxide generation by stimulating AT1 receptors in the vascular cells that leads to activation of NAD(P)H oxidase. In addition, Ang II can also directly activate $\mathrm{NAD}(\mathrm{P}) \mathrm{H}$ by inducing translocation of GTPase rac1 protein to the cell membrane,${ }^{19}$ or by phosphorylating and translocating $\mathrm{p} 47$ phox to cell membrane. ${ }^{20}$ Activation of NAPDH oxidase provides superoxide that reacts with eNOS-derived NO and leads to eNOS uncoupling in hypertension. ${ }^{21}$ In addition, xanthine oxidase expression and activity are also increased by Ang II in a NADPH oxidase-dependent manner. ${ }^{22}$ Thus ACEI may decrease the oxidative stress in part by limiting Ang II induced superoxide production by $\mathrm{NAD}(\mathrm{P}) \mathrm{H}$ oxidase and reduce the downstream effects of superoxide. ${ }^{20}$ ACEI therapy may also down regulate activation of redox-sensitive proinflammatory signals and limit lipid peroxidation and peroxynitrite generation. This study brings new evidence in humans that supports the hypothesis that ACEI increase antioxidant activity and decrease lipid peroxidation.

In this study, we found some decrease in plasma MDA levels and increase in antioxidant enzymes in atenolol treatment group. However these changes were not significant compared to pretreatment values. The reduction in plasma MDA values and increased levels of antioxidant enzymes after atenolol treatment might be explained by the fact that increased circumferential blood vessel wall stretch in hypertension leads to activation of NADPH oxidase via integrin-linked kinase 1 (ILK-1) Rac-1 pathway. $^{23}$ Atenolol, by normalizing blood pressure, decreases this wall stretch and reduces the activation of NADPH oxidase via this pathway. However, this pathway appears to play a minor role in ROS production in hypertension as normalization of blood pressure by atenolol could not reduce the oxidative stress significantly.

Studies with nebivolol and carvedilol have shown that these agents reduce oxidative stress. However the potential antioxidant effects of these agents is attributed to their direct ROS-scavenging action, greater degree of lipophilicity, specific physicochemical interactions with the membrane, and distinct and favorable effects on the kinetics of NO generation and metabolism, independent of $\beta_{1}$-blockade activity. ${ }^{24,25}$ Lack of such ancillary properties in atenolol and its hydrophilic nature may explain the ineffectiveness of atenolol in reducing oxidative stress.

\section{CONCLUSION}

Oxidative stress is significantly increased in patients of essential hypertension. Treatment with enalapril significantly reduced the oxidative stress whereas atenolol failed to show any significant effect on these parameters despite comparable reduction in blood pressure in both the groups. Thus treatment with enalapril reduces oxidative stress in hypertension independent of its blood pressure lowering effect. Thus we may conclude that treatment with enalapril, in contrast to atenolol, may prove beneficial by preventing oxidative stress related complications of hypertension in view of life long therapy required for the treatment of hypertension.

\section{ACKNOWLEDGEMENTS}

We are grateful to Dr. Shailesh M Patel, Professor \& Head, Department of Biochemistry, Government Medical College, Surat for his meticulous guidance on the biochemistry methods used in this study.

Funding: None

Conflict of interest: None declared

Ethical approval: The study was approved by the institutional ethical committee

\section{REFERENCES}

1. Opari1 S, Zaman MA, Calhoun DA. Pathogenesis of hypertension. Ann Intern Med 2003;139:761-76.

2. Savoia C, Schiffrin EL. Inflammation in hypertension. Curr Opin Nephrol Hypertens 2006; $15: 152-8$.

3. Hamilton CA, Miller WH, Al-Benna S, Brosnan MJ, Drummond RD, McBride MW, Dominiczak AF. Strategies to reduce oxidative stress in 
cardiovascular disease. Clin Sci (Lond) 2004;106:219-34.

4. Asayama K, Dobashi K, Hayashibe H, Kato K. Effects of beta-adrenergic blockers with different ancillary properties on lipid peroxidation in hyperthyroid rat cardiac muscle. Endocrinologia Japonica 1989;36:687-94.

5. Zhang $\mathrm{C}$, Xie $\mathrm{HH}, \mathrm{Lu}$ ZA, Zhu MJ, Su DF. Inhibition of inflammation contributes to organ protection of atenolol in sinoaortic-denervated rats. J Cardiovasc Pharmacol 2004;43:663-8.

6. Pasini AF, Garbin U, Nava MC, Stranieri C, Davoli A, Sawamura T, et al. Nebivolol decreases oxidative stress in essential hypertensive patients and increases nitric oxide by reducing its oxidative inactivation. J Hypertens 2005;23:589-96.

7. Guoxiong C, Jun PU, Chentai Z, Yexin MA, Zaiying LU. Effects of $\beta$-blockers on the oxidative stress in the atherosclerotic rabbit. Journal of Clinical Cardiology. 2007-12.

8. Rugale C, Cordaillat M, Mimuran A, Jover B. Prevention and reversal by enalapril of target organ damage in angiotensin II hypertension. J Renin Angiotensin Aldosterone Syst 2005;6:154-60.

9. de Cavanagh EMV, Inserra F, Ferder L, Fraga C. Enalapril and captopril enhance glutathionedependent antioxidant defenses in mouse tissues. Am J Physiol 2000;278:R572.

10. Napoli C, Sica V, de Nigris F, Pignalosa O, Condorelli M, Ignarro LJ, Liguori A. Sulfhydryl angiotensin-converting enzyme inhibition induces sustained reduction of systemic oxidative stress and improves the nitric oxide pathway in patients with essential hypertension. Am Heart J 2004;148:e5.

11. Ohkawa H, Ohishi N, Yagi K. Assay for lipid peroxides in animal tissues by thiobarbituric acid reaction. Anal Biochem 1979;95:351-8.

12. Marklund $\mathrm{S}$, Marklund G. Involvement of superoxide anion radical in the autoxidation of pyrogallol and a convenient assay of superoxide dismutase. Eur J Biochem 1974;47:469-76.

13. Nandi A, Chatterjee IB. Assay of superoxide dismutase activity in animal tissue. J Bio Sci 1988;13:305-15.

14. Sinha AK. Colorimetric assay of catalase. Anal Biochem 1972;47:389-94.

15. M Touyz RM, Briones AM. Reactive oxygen species and vascular biology: implications in human hypertension. Hypertens Res 2011;34:5-14.
16. Park YM, Lim BH, Touyz RM, Park JB. Expression of NAD $(\mathrm{P}) \mathrm{H}$ Oxidase Subunits and Their Contribution to Cardiovascular Damage in Aldosterone/Salt-Induced Hypertensive Rat. J Korean Med Sci 2008;23:1039-45.

17. Armas-Padilla MC, Armas-Hernandez MJ, SosaCanache B, Cammarata R, Pacheco B, Guerrero J, et al. Nitric oxide and malondialdehyde in human hypertension. Am J Ther 2007;14:172-6.

18. Djordjevic VB, Pavlovic D, Pejovic M, Cvetkovic $\mathrm{T}$, Lecic N, Deljanin-Ilic M. Changes of lipid peroxides and antioxidative factor levels in blood of patients treated with ACE inhibitors. Clin Nephrol 1997;47:243-7.

19. Touyz RM, Yao G, Schiffrin EL. c-Src induces phosphorylation and translocation of $\mathrm{p} 47$ phox: role in superoxide generation by angiotensin II in human vascular smooth muscle cells. Arterioscler Thromb Vasc Biol 2003;23:981-7.

20. Hosomi N, Mizushige K, Ohyama H, Takahashi T, Kitadai M, Hatanaka Y, et al. Angiotensinconverting enzyme inhibition with enalapril slows progressive intima-media thickening of the common carotid artery in patients with non-insulindependent diabetes mellitus. Stroke 2001;32:153945.

21. Landmesser U, Dikalov S, Price SR, McCann L, Fukai T, Holland SM, Mitch WE, Harrison DG. Oxidation of tetrahydrobiopterin leads to uncoupling of endothelial cell nitric oxide synthase in hypertension. J Clin Invest 2003;111:1201-9.

22. Landmesser U, Spiekermann S, Preuss C, et al. Angiotensin II induces endothelial xanthine oxidase activation. Role for endothelial dysfunction in patients with coronary disease. Arterioscler Thromb Vasc Biol 2007;27:943-8.

23. Brandes RP. A new pixel in the puzzle. How increased vascular pressure induces oxidative stress. Hypertension 2009;54:964-7.

24. Mason RP, Kubant R, Jacob RF, et al. Effect of nebivolol on endothelial NO and peroxynitrite release in hypertensive animals: Role of antioxidant activity. J Cardiovasc Pharmacol 2006;48:862-9.

25. Groot AA, Mathy MJ, van Zwieten PA, et al. Antioxidant activity of nebivolol in the rat aorta. $\mathrm{J}$ Cardiovasc Pharmacol 2004;43:148-53.

doi:10.5455/2319-2003.ijbcp20130604

Cite this article as: Deoghare S, Kantharia ND.

Effect of atenolol and enalapril treatment on oxidative stress parameters in patients with essential hypertension. Int $\mathrm{J}$ Basic Clin Pharmacol 2013;2:252-6. 